\title{
Data Updating Method of Earthquake Loss Estimation Based on Open Information
}

\section{Shizhou Yu}

Key Laboratory of Earthquake Engineering and Engineering Vibration, Institute of Engineering Mechanics, China Earthquake Administration, Harbin, China

\section{Email address: \\ zhxszy@126.com}

\section{To cite this article:}

Shizhou Yu. Data Updating Method of Earthquake Loss Estimation Based on Open Information. Science Discovery. Vol. 7, No. 3, 2019, pp. 172-177. doi: 10.11648/j.sd.20190703.17

Received: April 21, 2019; Accepted: May 24, 2019; Published: June 15, 2019

\begin{abstract}
Accurate basic data is the basis of earthquake loss estimation. Due to the long construction period and the difficulty of sharing \& updating of data base, the work of earthquake loss estimation will be affected seriously. To address this problem,in this paper, the open Information which can be used for earthquake loss assessment has been investigated, the influence of data change trend has been analysed with examples, in the end, the updating method of basic data based on public information has been given. Finally, two examples of data updating based on administrative region and km grid are given separately, and further work idea has been discussed for application of the data updating method. The study will be benefit to the prediction of earthquake damage in future and the estimation of economic loss after earthquake.
\end{abstract}

Keywords: Open Information, Earthquake Loss Estimation, Basic Data, Data Updating Method

\section{基于公开信息的地震损失评估数据更新方法}

余世舟

地震工程与工程振动重点实验室, 中国地震局工程力学研究所, 哈尔滨, 中国

\section{邮箱}

zhxszy@126.com

摘要: 准确的基础数据是地震损失评估工作的基础, 但数据库的建设周期长以及共享和更新困难将影响评估工作的顺 利开展。本文针对这一问题, 调研了可用于地震损失评估的公开数据; 举例分析了数据变化趋势的影响; 给出了基于 公开信息的基础数据的更新方法。最后, 分别给出了基于行政区域和公里网格的数据更新算例, 提出了进一步的工作 设想, 便于数据更新方法的实际应用。本研究满足了震害预测及震后损失评估中对基础数据的需求。

关键词: 公开信息, 地震损失评估, 基础数据, 数据更新方法

\section{1. 引言}

我国地震活动频度高、强度大，大陆 $\mathrm{VI}-\mathrm{IX}$ 度地震 烈度区面积占全部国土面积的 $80 \%$ 。近年来, 地震造成了 大量的人员伤亡和经济损失。为了减少地震损失，震前的 地震损失预测和震后的损失预估工作是震前准确地评估
地震风险, 震后开展有效应急措施的依据。因此, 评估数 据的准确、详实直接关系到评估结果的可信性。

我国从“七五”期间就开展了区域综合地震数据库建 设工作 [1-2], 到2007年底, 已经初步完成了包含基础地理 信息、社会经济统计、地震基础数据、工程地震资料、灾 害影响背景、灾害相关因素、救灾力量、震时紧急联络和 
地震应急预案与法规等 9 大类 42 小类的各级抗震救灾指挥 部地震应急基础数据库的主要建设任务 [3-5]。之后也开展 了进一步的相关的工作 [6]。

但已有基础数据还存在很多不足，如数据的完备性、 及时更新维护、共享性等, 降低了其合理、高效利用的价 值。数据库的建设周期长以及共享和更新困难将影响地震 损失评估工作的顺利开展, 针对这一问题, 尝试发掘可用 于地震损失评估的公开数据, 分析数据变化趋势, 给出基 于公开信息的基础数据的更新方法, 弥补既有数据存在的 不足[7-8]。

\section{2. 公开数据}

公开数据选取的依据主要是考虑常用的地震损失评 估方法中使用的参数, 直接使用或经过转换公开数据, 进 而得到需要基础数据。

目前, 国内外估计地震损失的方法主要按是否考虑结 构易损性的两类。考虑结构易损性的, 通过结构破坏等级、 人员伤亡比、损失比等估算地震损失; 不考虑结构易损性
的, 多是通过历史震例统计分析给出, 基于人口数量、GDP、 地震烈度等估算。

公开数据的种类很多, 这里基于易于获取和转换的类 别, 满足损失评估的基础数据需求, 给出数据种类和来源。

\section{1. 年鉴数据}

年鉴是公开数据种类中最为常见并被广泛采用的一 种数据形式。内容丰富, 一般分为 20 余个篇章, 于不同年 份根据经济社会发展的不同情况略有调整。按区域可分为 全国、省、市等多层级年鉴。可以通过资料数据购买或统 计部门网站下载获得。

可提取如人口、人口密度、GDP、人均GDP等数据用 于震灾损失评估的基础数据。但由于年鉴层级多，且基于 行政区域给出, 越高的层级数据仅细分到下一级, 而地市 的年鉴数量多, 年份或有缺失, 难以收集。

如图1中给出的四川省统计局网站公开的统计年鉴数 据, 省级的年鉴数据相对年份比较齐全, 数据格式规范。 多为表格、文档, 以网页检索形式给出, 方便提取数据。 但较早的年份数据也有以图片形式给出, 提取效率较低。
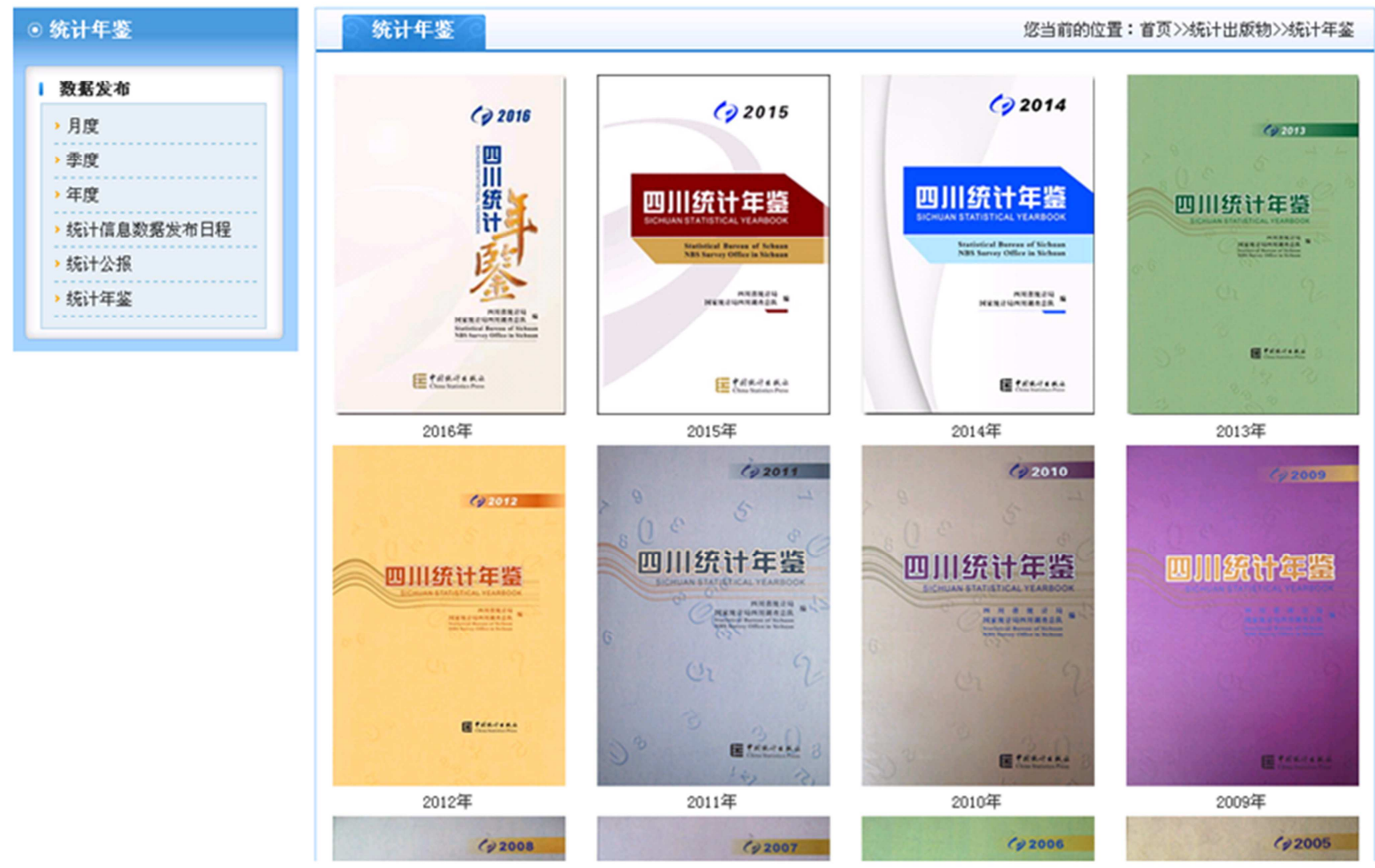

图1 四川省统计局网站公开的统计年鉴数据。

\section{2. 其他数据}

年鉴的数据相对齐全, 基本能满足地震损失评估方法 的参数需求, 但需要更专业的图层数据或高精度的分布数 据时, 年鉴数据就很难满足需要了。

公开的数据种类很多，除上述年鉴中可提取的数据， 还有高程数据、植被类型数据、土壤数据、城市空气质量
监测数据、卫星遥感影像数据、地形地貌数据、水系流域 空间分布数据、道路数据等等。各行业在这些数据利用方 面也开展了很多相关研究[9-12]。根据实际需求分析这些 数据的相关性, 可转换出满足一定精度需求的其他数据, 弥补已有数据使用的不足。如图2中全国土地利用空间分 布数据(数据来源: 中国科学院资源环境科学数据中心)。 


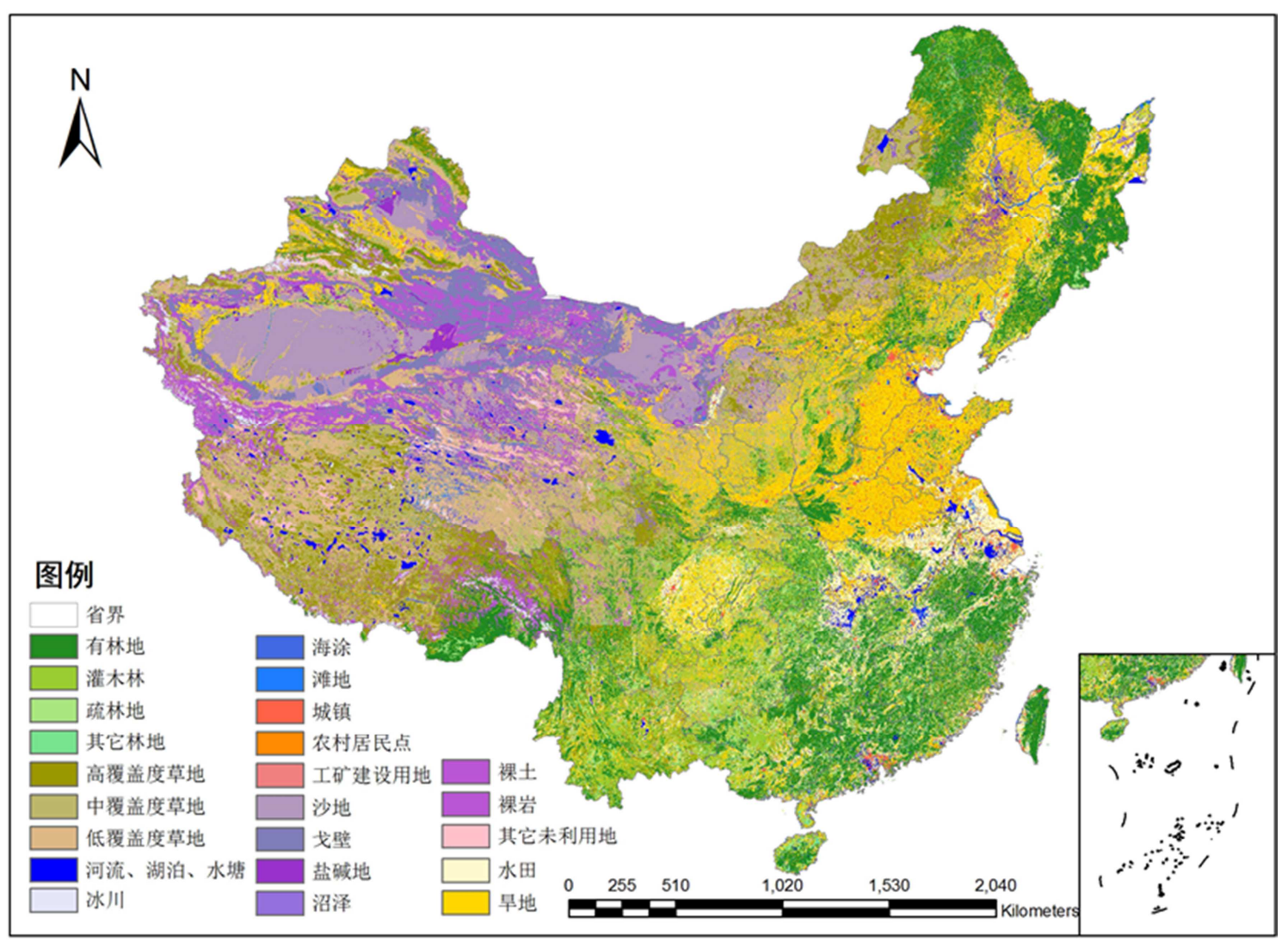

图2 全国土地利用空间分布图。

\section{3. 数据更新方法}

已有基础数据由于数据库建设时间早, 缺少必要的数 据维护与更新, 不能很好反映震时应急评估对参数准确性 的需求。而震害损失预测工作是对当前或未来可能发生的 地震评估其损失, 既有数据的使用就需要考虑数据年度变 化趋势, 更新已有数据。

前述公开数据中, 年鉴数据的年份数据相对比较齐全。 但如需更精细的数据, 则需要地市级的年鉴, 其数量多, 年份或有缺失, 难以收集。而对于专业的图层信息及高精 度的分布数据, 更新周期较大。对于缺失年份和未来年份 预期的数据需要依据年度变化趋势估算得到。

这里以人口的数据分析年度变化趋势及已有数据更 新的方法。

\section{1. 数据年度变化趋势}

年鉴中各行政区域人口数据将用于更新已有行政区 域数据, 也可进行公里网格化的数据分配。当所需年份数 据缺失的时候, 可依据前后多个年份的数据拟合分析给出。 下面以四川省及成都市的人口数据说明年度趋势变化和 数据处理的方法。

为了对比分析，从年鉴中提取四川省及成都市 2005 年至 2015 年户籍人口数据和四川省及成都市 2006 年至 2015 年常住人口数据(2005年数据缺失), 如表 1 和表 2 所示。
表1 四川省及成都市2005年至2015年户籍人口数(万人)。

\begin{tabular}{lll}
\hline 年份 & 四川省 & 成都市 \\
\hline 2015 & 9102.0 & 1228.1 \\
2014 & 9159.1 & 1210.7 \\
2013 & 9132.6 & 1188.0 \\
2012 & 9097.4 & 1173.4 \\
2011 & 9058.4 & 1163.3 \\
2010 & 9001.3 & 1149.1 \\
2009 & 8984.7 & 1139.6 \\
2008 & 8907.8 & 1125.0 \\
2007 & 8815.2 & 1112.3 \\
2006 & 8722.5 & 1103.4 \\
2005 & 8642.1 & 1082.0 \\
\hline
\end{tabular}

表2 四川省及成都市 2006 年至 2015 年常住人口数(万人)。

\begin{tabular}{lll}
\hline 年份 & 四川省 & 成都市 \\
\hline 2015 & 8204.0 & 1465.8 \\
2014 & 8140.2 & 1442.8 \\
2013 & 8107.0 & 1429.8 \\
2012 & 8076.2 & 1417.8 \\
2011 & 8050.0 & 1407.1 \\
2010 & 8041.8 & 1404.8 \\
2009 & 8185.0 & 1286.6 \\
2008 & 8138.0 & 1270.6 \\
2007 & 8128.6 & 1218.4 \\
2006 & 8167.4 & 1209.2 \\
\hline
\end{tabular}

依据这些数据可以给出散点图如图3至图6, 并画出趋 势线。通过已有数据的拟合分析, 可以给出所需年份数据 的计算公式(1)至公式(4)。

由四川省及成都市的户籍人口和常住人口变化情况 可以看出： 
1)成都市户籍人口和常住人口随着城市发展, 是逐年 递增的趋势。

2)四川省的常住人口在2008年前后异常变化，2008年 汶川地震影响，对户籍人口影响不大。

3)但四川省非户籍人口的变化导致常住人口在 2008 年后期及 2009 年数量突增, 随后突然减少, 2010年后逐渐 恢复。

从数据变化的趋势可以看出 2008 年汶川地震对人口 数据变化的影响。

1)由于地震受灾面积大, 波及四川省大部分地区。虽 有大量人员伤亡, 但占全省户籍人口比例较小, 几乎看不 到数据变化。

2)但四川省在震后大量援建人员的入住、非户籍人口 的离开有关，任务完成援建人员又全部撤离。造成常住人 口激增, 随后突降的数量变化, 与实际情况相符。

3)而成都市, 无论户籍人口还是常住人口变化都比较 平缓, 这与成都市远离震中, 且受灾影响不大有关。几乎 没有受到援建人员入住与撤离的影响。

因此通过已有数据的数据拟合，给出变化趋势线，求 出需要年份的数据具有一定的可信性。求得的数据可用于 对历史震例年份的地震损失对比分析, 或对未来年份的数 据推测，用于地震损失的预测。

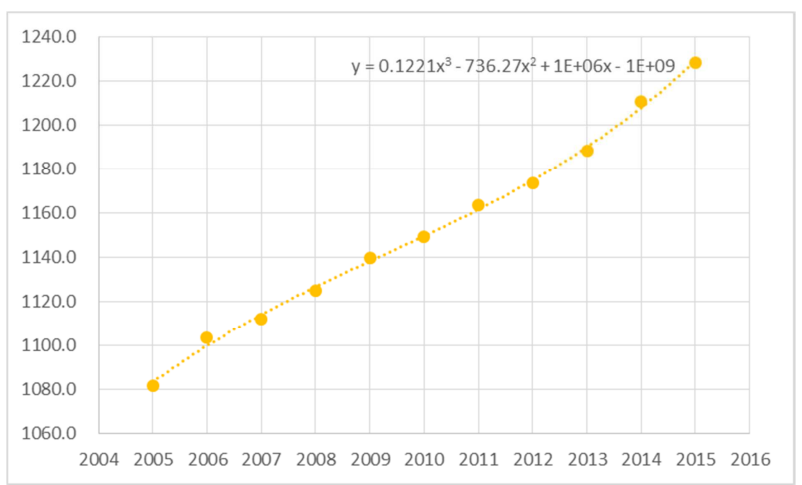

图3 成都市2005年至 2015 年户籍人口数变化。

多项式拟合得到的成都市 2005 年至 2015 年户籍人口 数变化趋势线公式为

$$
y=0.1221 x^{3}-736.27 x^{2}+10^{6} x-10^{9}
$$

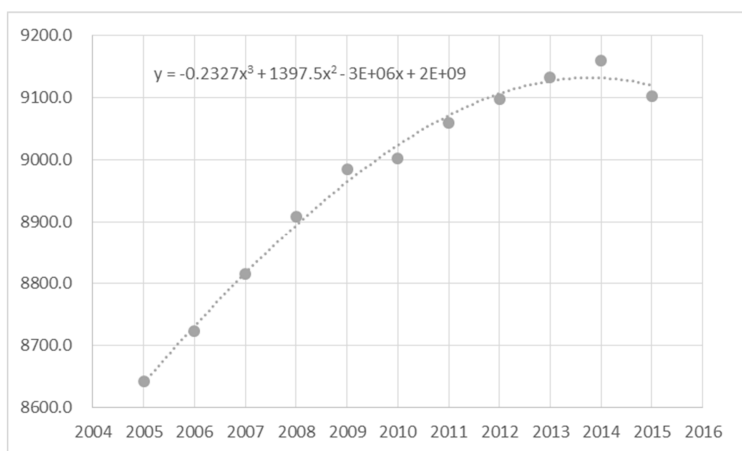

图4 四川省2005年至2015年户籍人口数变化。
多项式拟合得到的四川省2005年至2015年户籍人口 数变化趋势线公式为

$$
y=-0.2327 x^{3}+1397.5 x^{2}-3 \times 10^{6} x-2 \times 10^{9}
$$

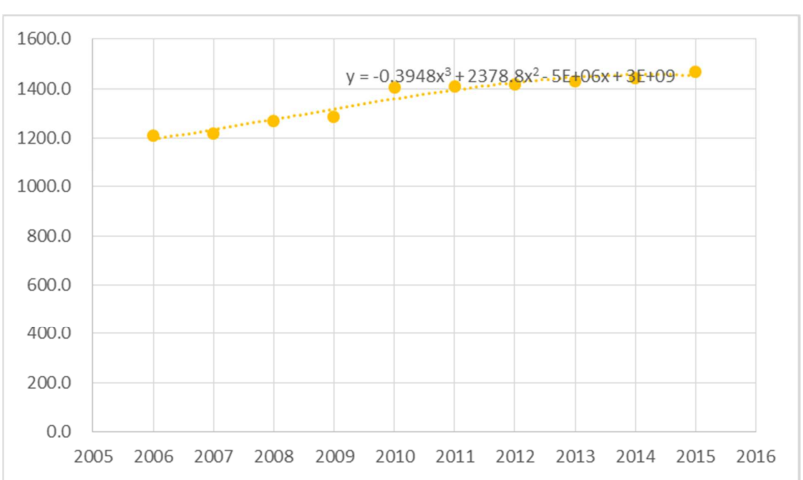

图5 成都市2006年至2015年常住人口变化。

多项式拟合得到的成都市 2006 年至 2015 年常住人口 变化趋势线公式为

$$
y=-0.3948 x^{3}+2378.8 x^{2}-5 \times 10^{6} x+4 \times 10^{9}
$$

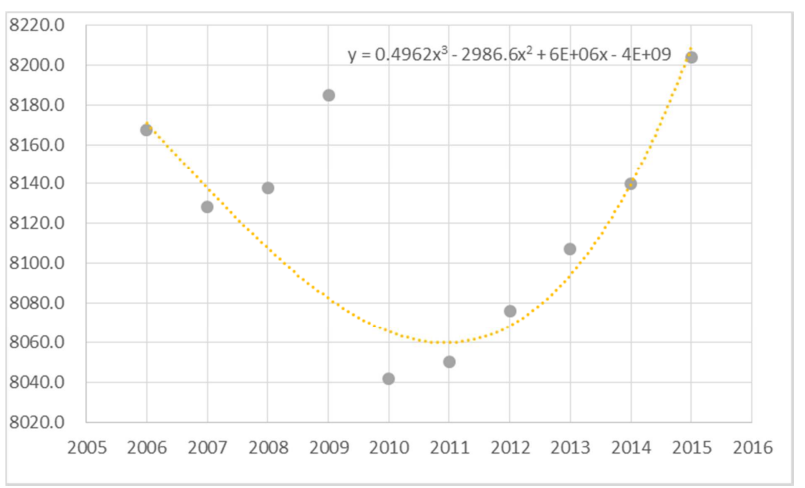

图6 四川省2006年至2015年常住人口变化。

多项式拟合得到的四川省2006年至2015年常住人口 变化趋势线公式为

$$
y=0.4962 x^{3}-2986.6 x^{2}+6 \times 10^{6} x-4 \times 10^{9}
$$

\section{2. 基于年度趋势预测的数据更新}

通过基础数据的年度变化趋势拟合公式, 就可以求出 所需年份的数据。进而对已有数据进行数据更新。

已有数据形式主要有三种: 基于行政区划单元的基础 数据、精细化到公里网格单元的基础数据、单体建筑数据。

对于前两类数据, 可以通过拟合数据进行更新。其中 基于行政区划单元的数据, 直接用拟合数据替换原有数据; 对于精细化到公里网格单元的基础数据, 按公式(5)进行数 据更新。

$$
p_{i j}=p_{i} \frac{p_{i j 0}}{\sum_{j=1}^{n} p_{i j 0}}
$$


式中, $p_{i}$ 为第 $i$ 个行政区域单元，通过拟合计算得到 的数据; $p_{i j}$ 为第 $i$ 个行政区域单元的第 $j$ 个网格单元更新后 的数据; $p_{i j 0}$ 为第 $i$ 个行政区域单元的第 $j$ 个网格单元更新 前的数据。

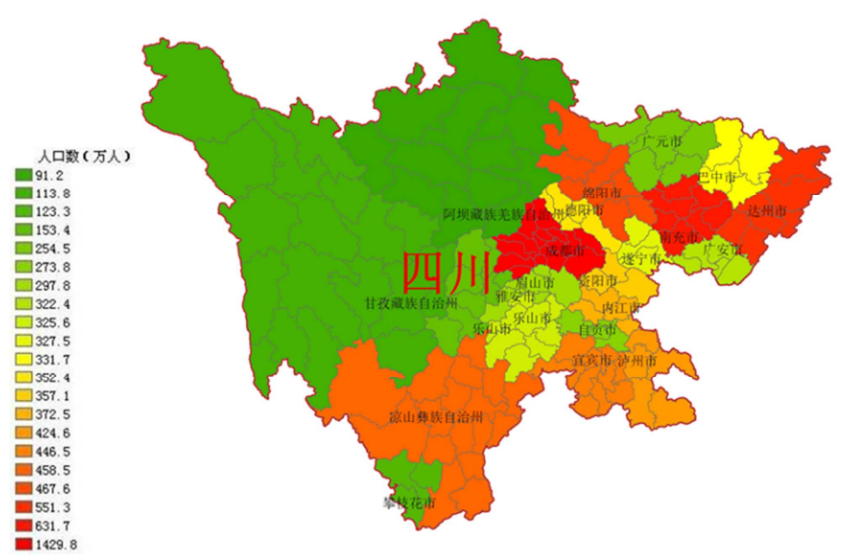

图7 四川省地市行政区域人口分布图。

以四川省人口行政区划单元数据和公里网格单元数 据为例, 把已有数据按上述方法及公式更新为 2013 年的人 口数据, 如图7和图8所示。

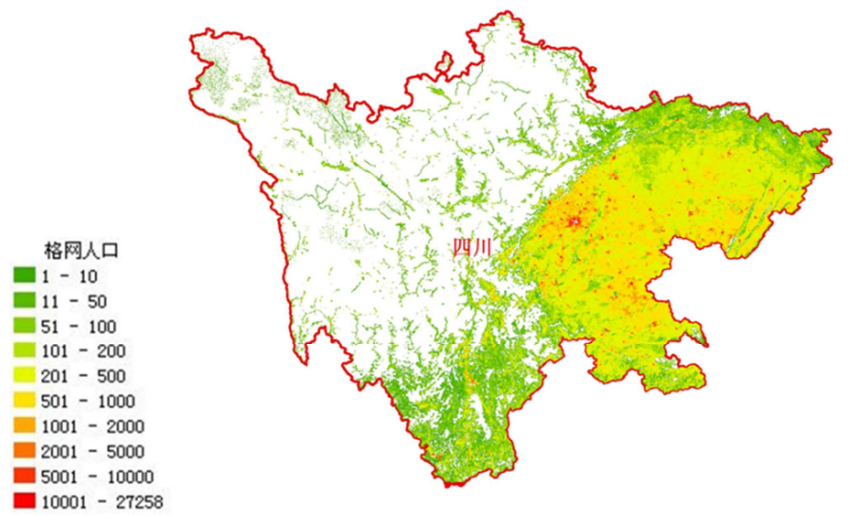

图8 四川省公里网格人口分布图。

\section{3. 分布数据更新}

对于精细化到公里网格单元的基础数据, 还应考虑区 域发展变迁的变化情况。在地震损失预测评估及震后应急 评估中, 公里网格数据逐渐被广泛采用, 得到了很好的精 细评估结果 $[13]$ 。同时, 其数据建设周期较长, 且不易更 新, 需要开发适宜的更新手段。如基于年度数据推算行政 区域总体数据, 依据其他公开分布数据作为分布更新的调 整。这方面的数据可以依据土地利用空间分布数据、夜晚 灯光空间分布数据等对评估参数数据进行数据转换的分 析, 之后再对年度拟合数据进行公里网格单元下的数据更 新[14-15]。限于篇幅, 这里不再复述。

\section{4. 实际应用}

综上, 基于公开信息对已有数据进行数据更新为用于 地震损失评估的年份数据是可行的。为了便于实际应用中
对地震损失评估工作时效性的要求。需要提前做好以下工 作:

1)基于公开数据，收集年份数据，建立用于地震损失 评估参数使用的年份数据库。

2)根据数据精细程度的需求, 可分省级、地市级、村 镇级等层级。

3)为保证数据拟合的效果, 需几年或逐年更新数据。

4)程序化的数据拟合算法、数据更新方法。

5)简化交互界面, 仅通过选取数据精度层级和数据年 份, 即可更新已有数据。

\section{4. 结论}

用于地震损失评估的基础数据, 由于数据库的建设周 期长以及共享和更新困难, 制约了数据的高效利用, 数据 的准确性差也直接影响评估结果的置信范围。本文对公开 数据的分析和初步给出了数据的更新方法。主要结论如下:

1)公开数据能满足已有数据更新的需求。除了符合常 用的损失评估参数数据外, 可有很多数据可用于直接或间 接的专业数据图层的转换和更新。

2)年度数据变化较大, 疏于维护、更新的基础数据将 影响评估结果的准确性。

3)即使最新的基础数据, 在预测未来可能发生地震的 损失和风险时, 也必须考虑年度变化趋势, 进行调整更新。

4)公开数据的发展趋势，从数据种类、即时性、获取 方式渠道等多方面都有很大的改进, 有益于已有数据的更 新, 甚至可直接利用或转换成其他专业基础数据。

5)开展进一步的实际应用工作，可使基础数据的更新 更为便利。满足震害预测及震后损失评估中对基础数据的 需求。

\section{致谢}

本文为中央级公益性科研院所基本科研业务费专项 资助项目《地震应急灾情获取技术初步研究》(2017D12) 的阶段性成果之一。

\section{参考文献}

[1] 李宜瑞, 牟其铎. 我国地震数据库建设及其应用综述 $[\mathrm{J}]$, 国际地震动态, 1993, 22(3) : 8-12.

[2] 修济刚, 杨憋源. 我国地震数据库建设工作进展述评 [J], 国 际地震动态, 1987, 16(12):3-17.

[3] 梁芳. 地震应急基础数据库的建设和发展, [J], 城市与减 灾,2013, 25(4):28-30.

[4] 聂高众, 陈建英, 李志强等. 地震应急基础数据库建设 [J], 地震，2002,22(3): 105-112.

[5] 帅向华, 姜立新, 王栋梁. 国家地震应急指挥软件系统研 究[J]. 自然灾害学报, 2009,18(3): 99-103. 
[6] 陈洪富, 孙柏涛,陈相兆. 基于 GIS 的地震基础数据库管理 系统术[J], 地震研究, 2004,37(4):648-653.

[7] 余世舟, 震后压埋人员状态及救援需求研究[R], 中国地震 局工程力学研究所, 哈尔滨, 2013: 5-6.

[8] 余世舟, 地震应急灾情获取技术初步研究 [R], 中国地震局 工程力学研究所, 哈尔滨, 2018: 24-25.

[9] 王 琪, 袁涛, 郑新奇. 基于夜间灯光数据的中国省域GDP 总量分析 [J]. 城市发展研究, 2013, 20(7) : 44- 48.

[10] Elvidge C D, Baugh K E, Kihn E A, et al. Relation between Stale-lite Observed Visible-near Infrared Emissions, Population, Economic Activity and Electric Power Consumption [J]. International Journal of Remote Sensing, 1997, 18(6): 1373-1379.
[11] 刘纪远, 张增祥, 徐新良. 21 世纪初中国土地利用变化的 空间格局与驱动力分析 [J]. 地理学报, 2009, 64(12): 1411-1420.

[12] 苏泳㜆, 王重, 张虹鸥, 陈修治, 林晖, 许喜逢. 基于 DMSP/OLS 夜间灯光数据提取城镇建设用地的邻域分析 法 $[J]$. 热带地理, 2015，35(2)：193-201.

[13] 刘如山, 南北地震带大震极灾区速判及灾情展布关键技术 研究[R], 中国地震局工程力学研究所, 哈尔滨, 2013: 180-188.

[14] 余世舟, 地震初期灾害损失及分布预评估方法研究[R], 中 国地震局工程力学研究所, 哈尔滨, 2017: 21-27.

[15] 刘如山, 余世舟, 颜冬启, 贺梦龙, 越潇, 李吉. 地震破 坏与经济损失快速评估精细化方法研究 [J], 应用基础与工 程科学学报, 2014,(5):916-927. 